\title{
Chronic Treatment with Interleukin-1 $\beta$ Induces Coronary Intimal Lesions and Vasospastic Responses in Pigs In Vivo The Role of Platelet-derived Growth Factor
}

\author{
Hiroaki Shimokawa, Akira Ito, Yoshihiro Fukumoto, Toshiaki Kadokami, Ryuichi Nakaike, Makoto Sakata, Tsuneo Takayanagi, \\ Kensuke Egashira, and Akira Takeshita \\ The Research Institute of Angiocardiology and Cardiovascular Clinic, Kyushu University School of Medicine, Fukuoka 812-82, Japan
}

\begin{abstract}
Studies in vitro have suggested that inflammatory cytokines may play an important role in the pathogenesis of atherosclerosis. However, little is known about their effects in vivo. Thus, the present study was designed to determine in vivo what histological and functional changes may be induced by chronic treatment with IL-1 $\beta$, one of the major inflammatory cytokines, and also to clarify what mechanisms are involved in those changes. Under aseptic conditions, proximal segments of the left porcine coronary arteries were gently wrapped with cotton mesh absorbing Sepharose beads either with or without recombinant human IL-1 $\beta$. From 1 to 4 wk after the operation, coronary vasospastic responses to intracoronary serotonin or histamine were noted at the IL$1 \beta$-treated site but not at the control site. Histologically, intimal thickening was greater at the IL-1 $\beta$-treated site than at the control site. Those functional and histological changes induced by the chronic treatment with IL-1 $\beta$ were significantly inhibited by the simultaneous treatment with a neutralizing antibody to either IL-1 $\beta$ or PDGF. These results indicate that chronic treatment with IL-1 $\beta$ induces coronary intimal lesions and vasospastic responses in porcine coronary arteries in vivo and also suggest that these changes are substantially mediated by PDGF. (J. Clin. Invest. 1996. 97:769-776.) Key words: arteriosclerosis • coronary vasospasm $\bullet$ cytokine $\bullet$ inflammation $\cdot$ coronary artery disease
\end{abstract}

\section{Introduction}

Atherosclerosis is an excessive inflammatory and proliferative response of the vascular wall to various forms of injury (1-3). Such injuries include not only mechanical but also inflammatory and immunological ones (1-3). We have previously developed a swine model of coronary artery spasm and thereby revealed a close relationship between coronary spasm and atherosclerosis (4-6). However, what aspect of coronary atherosclerosis is responsible for the occurrence of such spasms remains to be elucidated.

Address correspondence to Hiroaki Shimokawa, M.D., Research Institute of Angiocardiology and Cardiovascular Clinic, Kyushu University School of Medicine, 3-1-1 Maidashi, Higashi-ku, Fukuoka 81282, Japan. Phone: 81-92-641-1151; FAX: 81-92-633-2742.

Received for publication 7 March 1995 and accepted in revised form 26 October 1995.

J. Clin. Invest.

(C) The American Society for Clinical Investigation, Inc.

0021-9738/96/02/0769/08 \$2.00

Volume 97, Number 3, February 1996, 769-776
Recent studies in vitro have shown that inflammatory cytokines stimulate the proliferation of vascular smooth muscle cells, which suggests that they play an important role in the pathogenesis of atherosclerosis $(1-3,7,8)$. The inflammatory changes of the coronary artery have also been suggested to play an important role in the pathogenesis of coronary spasm and unstable angina (9-12). However, the in vivo effects of those inflammatory cytokines on the coronary artery remain to be determined. IL- $1 \beta$ is one of the major inflammatory cytokines found in atherosclerotic lesions $(13,14)$. Thus, the present study was designed to determine in vivo exactly what histological and functional changes may be induced by chronic treatment with IL-1 $\beta$ and to clarify what mechanisms are involved in those changes. For this purpose, we used a new method to chronically treat the coronary artery from the adventitial surface by locally applying IL-1 $\beta$ that had been bound to microbeads.

\section{Methods}

Animal preparation. 33 male Yorkshire pigs, 2-4 mo old and weighing 20-30 kg, were used for this study. They were sedated with the intramuscular administration of ketamine hydrochloride $(12.5 \mathrm{mg} / \mathrm{kg})$ and anesthetized with the intravenous administration of sodium pentobarbital $(25 \mathrm{mg} / \mathrm{kg})$. The animals were then intubated and ventilated with room air while oxygen was supplemented via a positive pressure respirator (Shinano Inc., Tokyo, Japan). Under aseptic conditions, a left thoracotomy was performed, and the proximal segments of the left anterior and circumflex coronary arteries were carefully dissected. The dissected segments of the coronary arteries were gently wrapped with a cotton mesh after absorbing $0.05 \mathrm{ml}$ of Sepharose beads (Pharmacia, Uppsala, Sweden) in suspension either with or without recombinant human IL-1 $\beta$ ( $2.5 \mu \mathrm{g}$ or $25 \mu \mathrm{g})$. The sites of the treatment with IL-1 $\beta$-bound and control beads were randomized. This experiment was reviewed and approved by the Committee of the Ethics on Animal Experiments in the Kyushu University School of Medicine and carried out under the control of the Guidelines for Animal Experiments in the Kyushu University School of Medicine and according to The Law (No. 105) and Notification (No. 6) of the Japanese Government.

Preparation of IL- $1 \beta$ beads. $1 \mathrm{~g}$ of Sepharose microbeads $(\mathrm{CNBr}-$ activated Sepharose 4B, 45-65 $\mu \mathrm{m}$ in diameter), which bind the amino residues of proteins, including cytokines, was added to $50 \mathrm{ml}$ of $1 \mathrm{mM} \mathrm{HCl}$ solution and centrifuged at 1,200 rpm for $5 \mathrm{~min}$ four times. The beads were then resuspended in $20 \mathrm{ml}$ of $\mathrm{NaHCO}_{3} / \mathrm{NaCl}$ solution with $1 \mathrm{mg}$ of IL- $1 \beta$. The beads were allowed to bind with IL-1 $\beta$ at room temperature for $1 \mathrm{~h}$ and then at $4{ }^{\circ} \mathrm{C}$ overnight. After centrifugation at $1,200 \mathrm{rpm}$ for $5 \mathrm{~min}$, the supernatant was separated and the concentration of the remaining IL-1 $\beta$ in the supernatant was measured by an ELISA (15). The IL-1 $\beta$-bound beads in the pellet were resuspended in $20 \mathrm{ml}$ of $\mathrm{NaHCO}_{3} / \mathrm{NaCl}$ solution and centrifuged at $1,200 \mathrm{rpm}$ for $5 \mathrm{~min}$ four times. Then the IL-1 $\beta$-bound beads were resuspended with Tris- $\mathrm{HCl}$ buffer solution for $1 \mathrm{~h}$ to block any remaining active sites. The IL- $1 \beta-$ bound beads were finally washed and resuspended so that the final concentration of IL- $1 \beta$ was $50 \mu \mathrm{g} / \mathrm{ml}$ or $500 \mu \mathrm{g} / \mathrm{ml}$. The number of IL- $1 \beta$ or control beads in the suspension 
was $\sim 70 / \mu$ l. All of the above preparations were performed under sterile conditions.

Bioavailability and pharmacokinetics of the IL-1 $\beta$ beads. In our bead preparation, IL- $1 \beta$ molecules are bound to Sepharose beads by a covalent bond at the amino residues of the proteins, and most of the IL- $1 \beta$ molecules are bound inside the beads and are biologically inactive. Our preliminary calculation showed that only $1.2 \%$ or less of the IL- $1 \beta$-bound beads are actually bound to the surface of the beads and are biologically active. Thus, if $2.5 \mu \mathrm{g}$ of IL-1 $\beta$ that is bound to the beads is applied to the coronary artery, $30 \mathrm{ng}$ or less of IL-1 $\beta$ is biologically active. Since the mean protein concentration of the porcine coronary artery we used in this study was $0.434 \mathrm{mg}$ protein $(n=$ 4), this means that the local active concentration of IL-1 $\beta$ was $69 \mathrm{ng} /$ $\mathrm{mg}$ protein. We determined by an ELISA assay that, in the injured rat carotid artery $24 \mathrm{~h}$ after balloon injury, the local IL-1 $\beta$ concentration was $0.6 \mathrm{ng} / \mathrm{mg}$ protein, whereas that in the contralateral uninjured carotid artery was $0.005 \mathrm{ng} / \mathrm{mg}$ protein $(n=3)$. Thus, the local active concentration of IL- $1 \beta$ was higher in our porcine model than in the rat injury model. It should be noted, however, that in our porcine model IL- $1 \beta$ molecules are present only on the adventitial surface of the coronary artery, whereas in the rat model they are present in the coronary artery and are all bioactive. Thus, we believe that the dose of IL- $1 \beta$ used in our study is of pathophysiological relevance.

We also confirmed that, 2 wk after the application of the IL- $1 \beta-$ bound beads to the coronary artery, no appreciable activity of recombinant human IL-1 $\beta(<20 \mathrm{pg} / \mathrm{mg}$ protein) was observed in the treated porcine coronary segment, as examined by an ELISA assay $(n=3)$. We also observed that the intensity of the immunostaining for human IL- $1 \beta$ on the microbeads gradually decreased 3 and $7 \mathrm{~d}$ after application of the IL-1 $\beta$-bound beads to the coronary artery and almost disappeared $2 \mathrm{wk}$ after the application. The antibody to human IL-1 $\beta$ does not cross-react with porcine IL-1 $\beta$.

Protocols. In the first protocol, the time course of the chronic treatment with IL-1 $\beta(2.5 \mu \mathrm{g}[\mathrm{n}=8]$ and $25 \mu \mathrm{g}[\mathrm{n}=4]$; the two doses of IL-1 $\beta$ were simultaneously examined in three animals) was examined. A coronary arteriographic study was performed every week for $4 \mathrm{wk}$ after the operation. In an additional three animals, in which the coronary arteries were treated with IL-1 $\beta$ beads $(2.5 \mu \mathrm{g})$ and control beads, the period of the observation was extended to $3 \mathrm{mo}$, and coronary arteriography was performed every month after the operation.

In the second protocol, the inhibitory effects of a neutralizing antibody to IL-1 $\beta(5.0 \mathrm{mg}, n=6)$ and to PDGF $(2.5 \mathrm{mg}, n=5)$ were examined. Since in the first protocol the angiographic stenosis and the vasospastic responses were noted throughout the study period, the experiments were terminated $2 \mathrm{wk}$ after the operation, and then the coronary morphology was examined.

In the third protocol, the inhibitory effects of nonimmune $\mathrm{IgG}$ (goat, $2.5 \mathrm{mg}, n=5$ ) and Fab fragments (goat, $2.5 \mathrm{mg}, n=5$ ) on the IL- $1 \beta$-induced coronary changes were examined. For the same reason mentioned in the second protocol, the experiments were terminated $2 \mathrm{wk}$ after the operation, and then the coronary morphology was examined.

Coronary arteriography. The animals were anesthetized and ventilated as described above, and selective coronary arteriography was performed. A preshaped Judkins catheter was inserted into the right or left femoral artery, and coronary arteriography in a left anterior oblique view was performed. Electrocardiograms (I, II, III, V1, and V6 leads) and blood pressure were continuously recorded throughout the experiments $(4-6,16)$.

Coronary vascular responses were examined in response to serotonin ( 1 and $3 \mu \mathrm{g} / \mathrm{kg}$ i.c.), histamine ( 1 and $3 \mu \mathrm{g} / \mathrm{kg}$ i.c.), and prostaglandin $\mathrm{F} 2 \alpha$ (5 and $50 \mu \mathrm{g} / \mathrm{kg}$ i.c.) (16). Coronary arteriography was performed $2 \mathrm{~min}$ after the intracoronary administration of serotonin, 1 min after that of histamine, and 5 min after that of PGF2 $\alpha$. Ischemic electrocardiogram $(E C G)^{1}$ changes were defined as a

1. Abbreviation used in this paper: ECG, electrocardiogram. $>1$-mm ST segment elevation or depression in more than two leads $(4-6,16)$.

Coronary diameter measurement. The cineangiograms were projected on a screen using a cineprojector (ELK-35CB; Nishimoto Sangyo Inc., Osaka, Japan), and an end-diastolic frame was selected and printed. The coronary luminal diameters were measured with a caliper $(4-6,16)$. Using this technique, excellent correlations between repeated measurements $(r=0.99)$ as well as between different observers $(r=0.98)$ were confirmed in the range of the coronary diameter from $0.98 \mathrm{~mm}$ to $5.58 \mathrm{~mm}$ (16). The degree of the constrictive response was expressed as the percent decrease in the luminal diameter from the control level. The coronary diameter was measured at the segments treated with IL-1 $\beta$ beads and control beads as well as at the untreated segments of a comparable diameter.

Histological examination. After the angiographic experiments, the heart was removed and the left coronary arteries were perfused via a constant-pressure perfusion system $\left(120 \mathrm{~cm} \mathrm{H}_{2} \mathrm{O}\right)$ with saline $(500 \mathrm{ml})$ and subsequently with $6 \%$ formaldehyde $(1,000 \mathrm{ml})$. After fixation, the left coronary arteries were cut transversely into segments at a 4-5-mm interval along their main trunk with a small amount of surrounding tissue. These segments were stained with hematoxylineosin, van Gieson's elastic, and $\alpha$-actin stainings for photomicroscopy.

The intimal and medial areas were measured in photomicrographs by a computer-assisted picture analysis system (Genlocker System; Sony, Tokyo, Japan). The degree of intimal thickening was expressed by the following three parameters: intimal area $\left(\mathrm{mm}^{2}\right)$, maximal intimal thickness $(\mathrm{mm})$, and percent intima. The latter was defined as the intimal area $\left(\mathrm{mm}^{2}\right)$ expressed as a percentage of the area $\left(\mathrm{mm}^{2}\right)$ delineated by the internal elastic lamina.

Drugs. The following drugs and antibodies were used: 5-hydroxytryptamine (serotonin), histamine, and prostaglandin F2 $\alpha$ (Sigma Chemical Co., St. Louis, MO), neutralizing antibody to human IL-1 $\beta$ (rabbit; Ohtsuka Pharmaceutical Co., Tokushima, Japan), neutralizing antibody to human PDGF-AB (goat; Upstate Biotechnology, Inc., Lake Placid, NY), nonimmune goat IgG (Sigma Chemical Co.), and Fab fragments of goat IgG (O.E.M. Concepts, Inc., Tomsriver, NJ).

The neutralizing antibodies, nonimmune $\mathrm{IgG}$, and $\mathrm{Fab}$ fragments were simultaneously applied to the coronary segment with the IL-1 $\beta$ suspension absorbed in the cotton mesh. The volume of the IL-1 $\beta$ suspension plus the above mentioned agents was limited to $<0.4 \mathrm{ml}$ to avoid the possible effects of dilution of the cytokine suspension. In addition, the same amount of the IL- $1 \beta$ suspension plus saline was always applied to the site treated with IL- $1 \beta$ alone.

According to the supplier, the antibody to human PDGF-AB also neutralizes porcine PDGF-AB, PDGF-AA, and PDGF-BB. We confirmed that this antibody to human PDGF-AB does not crossreact with other growth factors/cytokines, including IGF, TGF- $\beta 1$,

Table I. Coronary Diameters and Hemodynamic Variables (First Protocol)

\begin{tabular}{|c|c|c|c|c|c|c|}
\hline & \multicolumn{3}{|c|}{ Coronary diameter } & \multirow[b]{2}{*}{$\mathrm{mBP}$} & \multirow[b]{2}{*}{$\mathrm{HR}$} \\
\hline & & IL-1 $\beta$ & Control & No $T x$ & & \\
\hline & $n$ & & $\mathrm{~mm}$ & & $\mathrm{~mm} \mathrm{Hg}$ & per min \\
\hline $1 \mathrm{wk}$ & 7 & $2.83 \pm 0.24$ & $4.24 \pm 0.15$ & $4.05 \pm 0.14$ & $96 \pm 4$ & $125 \pm 3$ \\
\hline $2 \mathrm{wk}$ & 7 & $2.99 \pm 0.22$ & $4.21 \pm 0.14$ & $4.03 \pm 0.19$ & $103 \pm 5$ & $122 \pm 4$ \\
\hline $3 \mathrm{wk}$ & 5 & $3.14 \pm 0.34$ & $4.33 \pm 0.19$ & $4.37 \pm 0.27$ & $98 \pm 8$ & $125 \pm 7$ \\
\hline $4 \mathrm{wk}$ & 5 & $2.95 \pm 0.31$ & $4.28 \pm 0.24$ & $4.20 \pm 0.21$ & $110 \pm 7$ & $128 \pm 5$ \\
\hline
\end{tabular}

Data are expressed as mean \pm SEM. $I L-1 \beta$ and Control, the coronary segments treated with interleukin- $1 \beta$ and control beads, respectively; No $T x$, the untreated coronary segment; $m B P$ and $H R$, mean blood pressure and heart rate, respectively. 

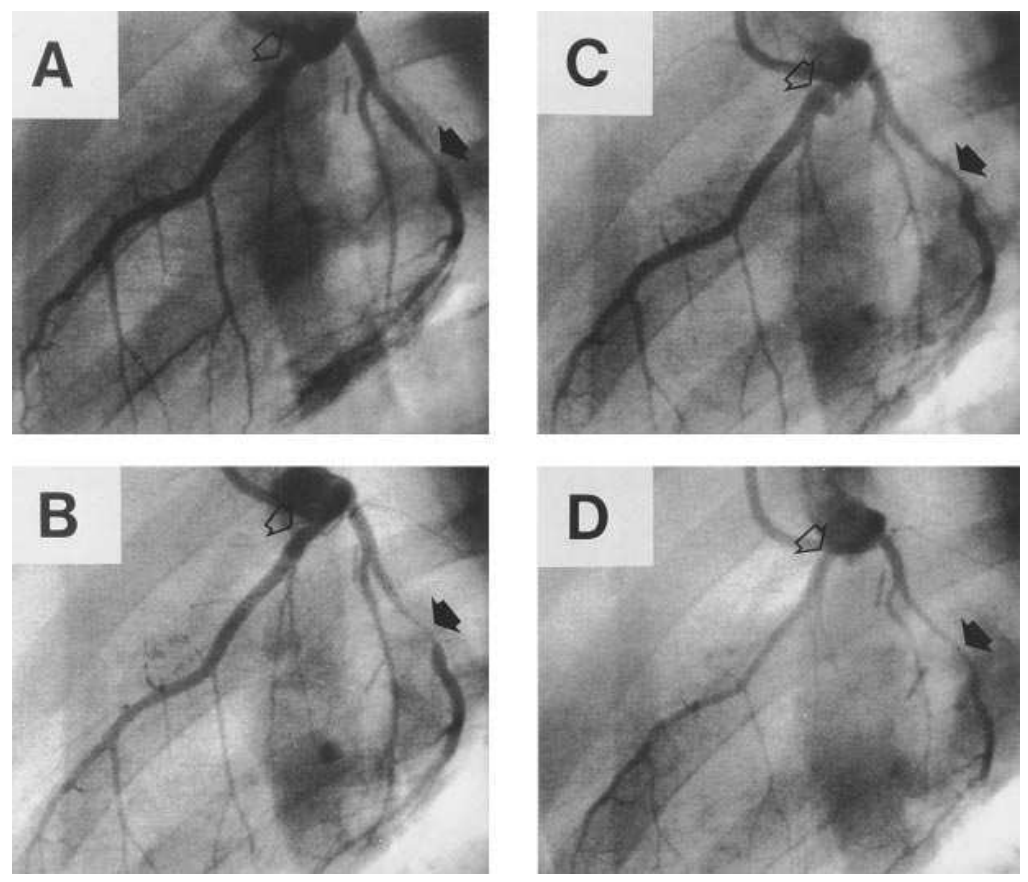

Figure 1. Coronary arteriograms in a pig 2 wk after the operation, under control conditions $(A)$ and after the intracoronary administration of serotonin $(3 \mu \mathrm{g} / \mathrm{kg})(B)$, histamine $(3 \mu \mathrm{g} / \mathrm{kg})(C)$, and prostaglandin $\mathrm{F} 2 \alpha(50 \mu \mathrm{g} / \mathrm{kg})(D)$. The black arrow indicates the site treated with IL-1 $\beta$ beads $(2.5 \mu \mathrm{g})$, and the translucent arrow indicates the site treated with control beads.

IL- $1 \alpha$, IL-1 $\beta$, IL- 6 , IL- 8 , and TNF- $\alpha .5 \mathrm{mg}$ of the antibody to PDGF neutralizes $50 \%$ of the biological activity of $5 \mathrm{ng}$ PDGF-AB. In a preliminary study, we tested two different doses $(500 \mu \mathrm{g}$ and $2.5 \mathrm{mg})$ of the antibody and found that the higher dose but not the lower one inhibited the IL-1 $\beta(2.5 \mu \mathrm{g})$-induced changes of the coronary artery. We also confirmed that the antibody to human IL-1 $1 \beta$ does not crossreact with porcine IL-1 $\beta$ or other growth factors/cytokines, including
PDGF-AB, IGF, TGF- $\beta 1$, IL- $1 \alpha$, IL-6, IL-8, and TNF- $\alpha .1 .17 \mu \mathrm{g}$ of the antibody completely neutralizes the biological activity of $50 \mathrm{pg}$ of human IL-1 $\beta$.

Statistical analysis. The results were expressed as the mean \pm SEM. Throughout the text and in the figures, $n$ represents the number of animals examined. Multiple comparisons were made by an analysis of variance for repeated examinations followed by post hoc tests for
A

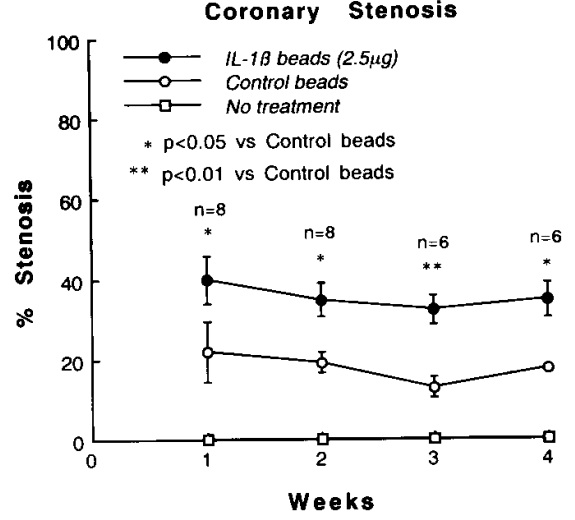

B

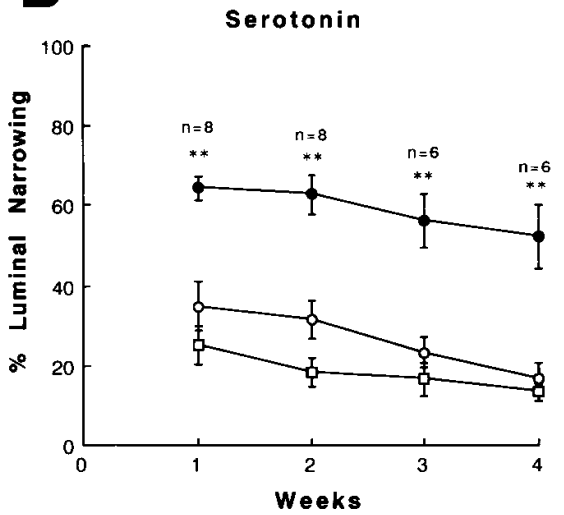

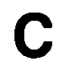

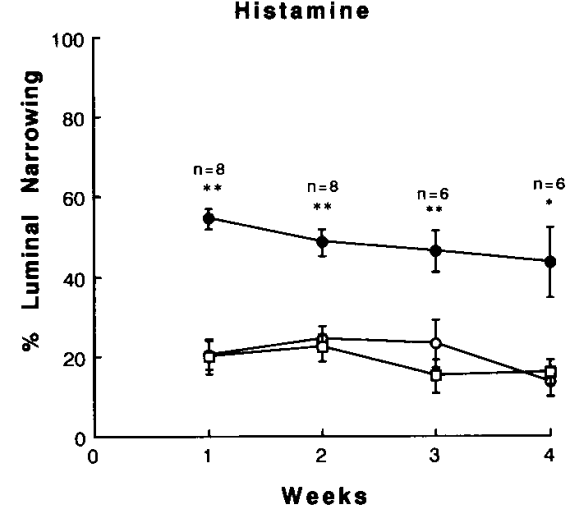

D

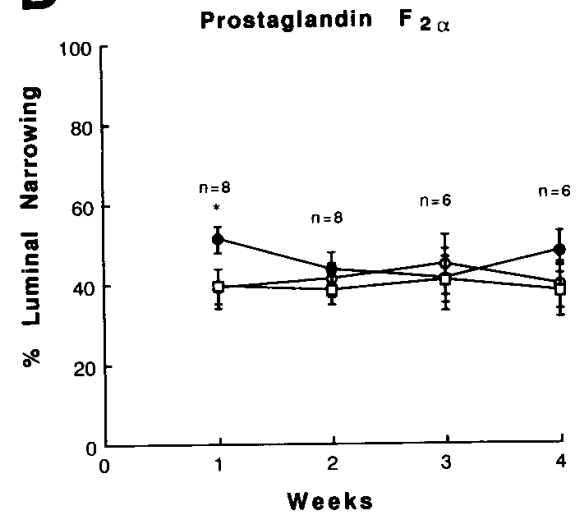

Figure 2. Coronary stenosis assessed by coronary arteriography $(A)$ and coronary vasoconstricting responses to the intracoronary administration of seroto$\operatorname{nin}(3 \mu \mathrm{g} / \mathrm{kg})(B)$, histamine $(3 \mu \mathrm{g} / \mathrm{kg})$ $(C)$, and prostaglandin $\mathrm{F} 2 \alpha(50 \mu \mathrm{g} / \mathrm{kg})$ (D). $I L-1 \beta$ beads, a coronary segment treated with IL-1 $\beta$ beads $(2.5 \mu \mathrm{g})$; Control beads, a coronary segment treated with control beads; No treatment, an untreated coronary segment. 


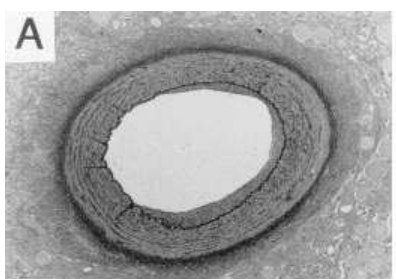

IL-1 $\beta$ beads

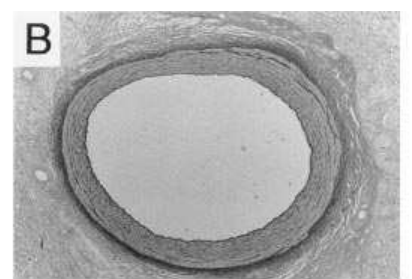

Control beads

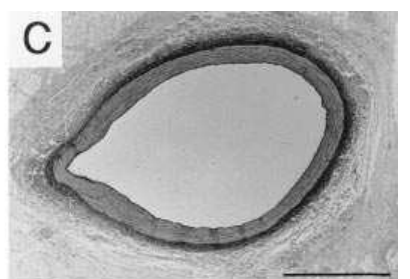

No treatment
Figure 3. Histology of the coronary artery segments treated with IL-1 $\beta$ beads $(2.5 \mu \mathrm{g})(A)$ and with control beads $(B)$, and of the untreated coronary artery segment $(C)$. The beads applied to the adventitial surface of the coronary artery can be seen in $A$ and $B$. The bar in $C$ represents $1 \mathrm{~mm}$. multiple comparisons (17). Paired data were analyzed by Student's $t$ test. A $P$ value of $<0.05$ was considered to be statistically significant.

\section{Results}

Coronary diameters and hemodynamic variables under control conditions in the first protocol are shown in Table I. After the operation, mild to moderate stenotic lesions were observed to develop angiographically at the surgically treated portions. The degree of stenosis was greater at the site treated with IL-1 $\beta$ $(2.5 \mu \mathrm{g})$ beads than at that treated with control beads (Figs. 1 and 2). Intracoronary serotonin and histamine caused marked coronary vasoconstriction at the site treated with IL-1 $\beta$ beads, whereas the autacoids caused only mild vasoconstriction at the sites treated with control beads to a similar extent at the untreated site (Figs. 1 and 2). In contrast, intracoronary prostaglandin F $2 \alpha$ caused a comparable degree of vasoconstriction at the site treated with IL-1 $\beta$ and control beads and at the untreated site (Figs. 1 and 2). Two animals died on the day after completion of the experiment $2 \mathrm{wk}$ after the operation. Although the causes of death were unknown, coronary vasospasm with ischemic ECG changes had been induced in both animals. The treatment with $25 \mu \mathrm{g}$ IL-1 $\beta$ did not cause any greater hyperconstrictive responses than the treatment with $2.5 \mu \mathrm{g}$ IL-1 $\beta$ (data not shown), which suggested that the coronary vasoconstricting responses reached a maximum after treatment with $2.5 \mu \mathrm{g}$ IL-1 $\beta$. The selective hyperconstrictions to the autacoids were highly reproducible and persisted for at least 4 wk after the operation (Fig. 2). The incidence of ischemic ECG changes during the occurrence of vasospasm was $43 \%$. In an additional three animals, the period of the observation was extended to $3 \mathrm{mo}$, and the vasospastic responses persisted throughout; however, the vasospastic responses tended to decrease over time (data not shown).
A histological examination revealed an intimal thickening at the surgically treated sites, which was greater at the IL-1 $\beta-$ treated than at the control site (Figs. 3 and 4). We determined that most of the cells in the thickened intima were smooth muscle cells because they were positive for $\alpha$-actin staining. The medial area also tended to increase in response to the IL$1 \beta$ treatment, but the increase did not reach a significant level (data not shown). An accumulation of inflammatory mononuclear cells (monocytes/macrophages and lymphocytes) at the adventitial surface was noted at the IL-1 $\beta$-treated site and, to a lesser extent, at the control bead-treated site.

Coronary diameters and hemodynamic variables under control conditions in the second protocol are shown in Table II. Simultaneous treatment with a neutralizing antibody to IL-1 $\beta$ $(5.0 \mathrm{mg}, n=6)$ and that to PDGF-AB $(2.5 \mathrm{mg}, n=5)$ significantly inhibited the vasospastic responses to the autacoids but not the vasoconstricting responses to prostaglandin F2 $\alpha$ (Fig. 5). Although those treatments with neutralizing antibodies did not significantly inhibit angiographic stenosis (Fig. 5), the treatment with a neutralizing antibody to IL-1 $\beta$ significantly inhibited the maximal intimal thickness and the percent intima, whereas the neutralizing antibody to PDGF significantly inhibited the intimal area and the percent intima (Figs. 6 and 7). Simultaneous treatment with either nonimmune $\operatorname{IgG}(n=$ $5)$ or Fab fragments $(n=5)$ did not inhibit the vasospastic responses or the histological changes induced by chronic treatment with IL-1 $\beta$ (data not shown).

\section{Discussion}

The novel findings of the present study were $(a)$ chronic treatment with IL-1 $\beta$ induced coronary intimal lesions and selective vasospastic responses to autacoids in vivo, and $(b)$ those changes were substantially mediated by PDGF. Thus, the
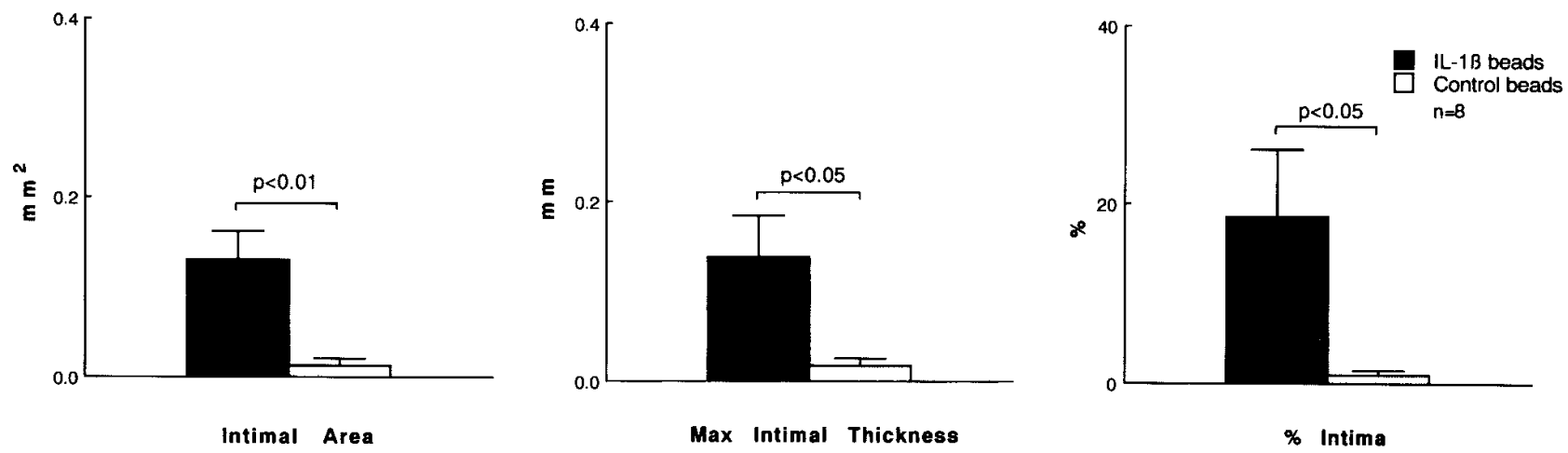

Figure 4. Quantitative analysis of the intimal thickening in the coronary artery segments treated with IL-1 $\beta$ beads $(2.5 \mu \mathrm{g})$ and control beads. The combined data, obtained from six animals $4 \mathrm{wk}$ after the operation and from two animals $2 \mathrm{wk}$ after the operation, are presented. $I L-1 \beta$ beads, a coronary segment treated with IL-1 $\beta$ beads $(2.5 \mu \mathrm{g})$; Control beads, a coronary segment treated with control beads. 


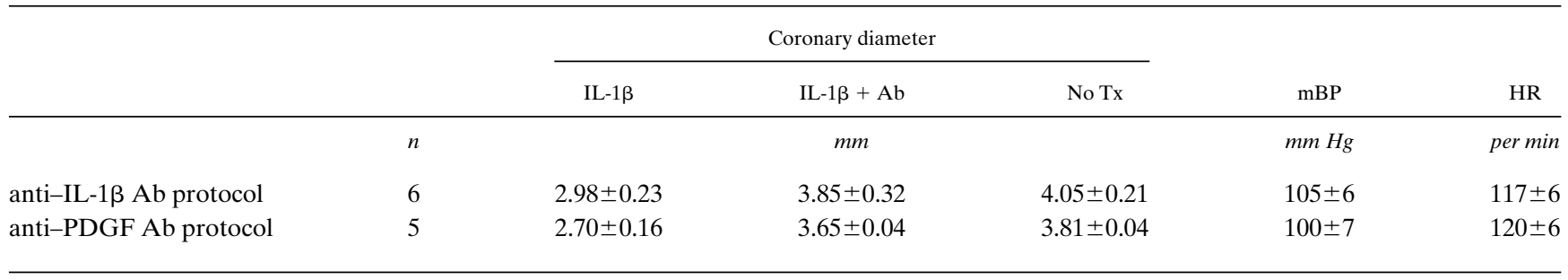

Data are expressed as mean \pm SEM. $I L-1 \beta$ and $I L-1 \beta+A b$, the coronary segments treated with IL-1 $\beta$ and IL- $1 \beta$ plus anti-IL-1 Ab or anti-PDGF $\mathrm{Ab}$, respectively; No $T x$, the untreated coronary segment; $m B P$ and $H R$, mean blood pressure and heart rate, respectively.

present study directly demonstrated the chronic effects of an inflammatory cytokine on the coronary artery in vivo.

Porcine model of coronary inflammatory lesion with IL-1 $\beta$. We decided to examine IL-1 $\beta$ as an inflammatory cytokine in this study because it is highly inflammatory and also one of the major inflammatory cytokines found in atherosclerotic lesions $(13,14)$. We used a new method to chronically treat the coronary artery from the adventitial surface by locally applying IL-1 $\beta$ that had been bound to microbeads. As mentioned in Methods, we believe that the local active concentration of IL-1 $\beta$ on the adventitial surface of the coronary artery was of pathophysiological relevance. We also recently observed the expression of mRNA for IL-1 $\beta$, using the reverse transcriptase-PCR method, in the human coronary specimens obtained by directional coronary atherectomy (unpublished observations). Although we used recombinant human IL-1 $\beta$ in this study, no species difference in the biological activities of the cytokine was observed (13). IL-1 $\beta$ may have a wide variety of biological effects on central nervous, metabolic, hematologic, and cardiovascular systems (13). In the cardiovascular system, IL-1 $\beta$ may have both a systemic and local effect (13). Since in the present study IL-1 $\beta$ bound to microbeads was applied only locally and externally to the coronary artery, no systemic effect of the cytokine was noted.

In the present study, the adventitial approach was used to chronically treat the coronary artery with IL-1 $\beta$. Other possible methods to chronically treat the coronary artery with IL-1 $\beta$ include a transfection of the IL- $1 \beta$ gene from the intimal surface using a perforated catheter $(18,19)$ and a chronic intracoronary infusion of IL-1 $\beta$ using an osmotic pump (20). However, the former method itself may cause significant endothelial and smooth muscle damage, whereas the latter method requires an
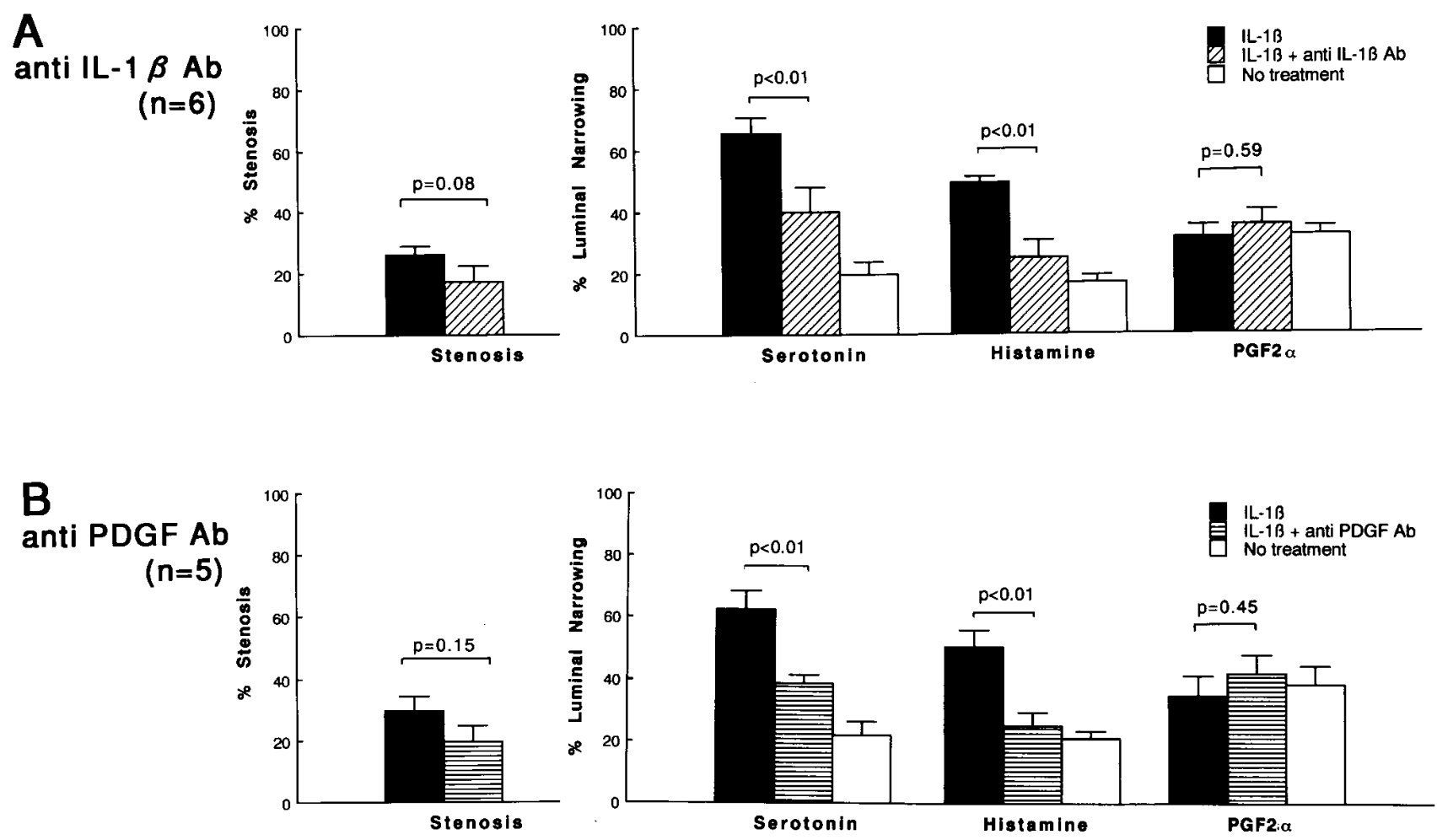

Figure 5. Coronary stenosis and coronary vasoconstricting responses to the intracoronary administration of serotonin $(10 \mu \mathrm{g} / \mathrm{kg})$, histamine $(10$ $\mu \mathrm{g} / \mathrm{kg})$, and prostaglandin $\mathrm{F} 2 \alpha(50 \mu \mathrm{g} / \mathrm{kg})$ in the protocols with neutralizing antibody to IL-1 $(A)$ and to PDGF $(B)$. IL-1 $\beta$, a coronary segment treated with IL-1 $\beta$ beads $(2.5 \mu \mathrm{g}) ; I L-1 \beta$ + anti $I L-1 \beta A b$, a coronary segment treated with IL-1 $\beta(2.5 \mu \mathrm{g})$ plus neutralizing antibody to IL-1 $\beta$ (5.0 $\mathrm{mg}) ; I L-1 \beta+$ anti PDGF $A b$, a coronary segment treated with IL-1 $\beta(2.5 \mu \mathrm{g})$ plus neutralizing antibody to PDGF (2.5 mg); No treatment, a coronary segment without any treatment. 


\section{anti IL-1B Ab A protocol}

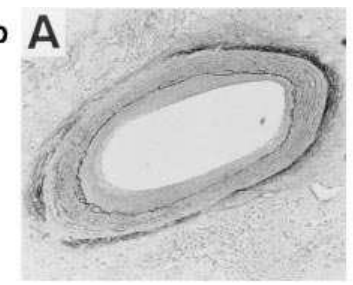

$I L-1 ß$

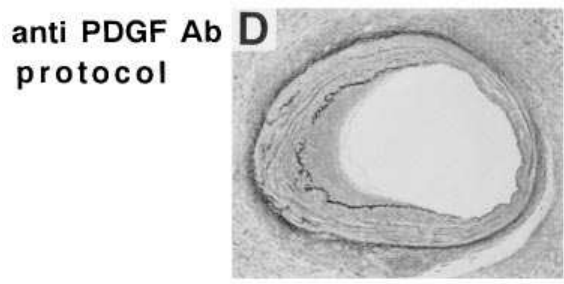

$I L-1 B$

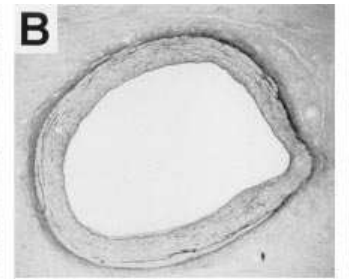

IL-1 B+ anti IL-1B Ab

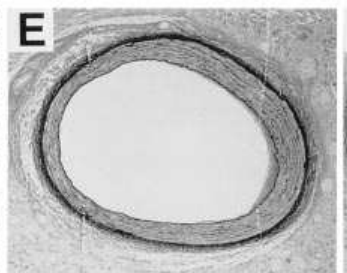

IL-1ß+anti PDGF Ab

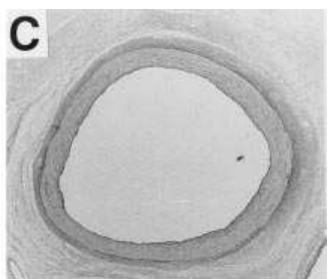

No treatment

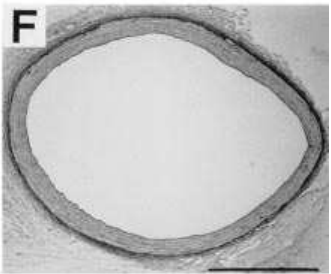

No treatment
Figure 6. Histology of the coronary artery segments treated with IL-1 $\beta(2.5 \mu \mathrm{g})(A, D), \mathrm{IL}-1 \beta(2.5$ $\mu \mathrm{g})$ plus neutralizing antibody to IL-1 $\beta(5.0 \mathrm{mg})(B)$, and IL-1 $\beta(2.5$ $\mu \mathrm{g})$ plus neutralizing antibody to PDGF-AB $(2.5 \mathrm{mg})(E)$, and of the untreated segments $(C, F)$. The bar in $F$ represents $1 \mathrm{~mm}$. infusion of very high doses of IL-1 $\beta$ for a longer period, which may cause unnecessary myocardial and systemic responses (13). Prescott et al. also successfully induced intimal lesions by implanting an endotoxin-soaked cotton thread in the adventitia of the rat femoral artery (21).

In our study, the morphological and functional changes of the coronary artery induced by recombinant human IL-1 $\beta$ were inhibited by the simultaneous treatment with a neutralizing antibody to IL-1 $\beta$. These results indicate that those changes of the coronary artery were induced by the effects of recombinant human IL-1 $\beta$. However, the activity of recombinant human IL-1 $\beta$ decreased to less than detection levels by 2 wk after the surgical application. This was consistent with the findings by Kasahara et al., in which the IL- $1 \beta$ activity of the lung tissue peaked by $3 \mathrm{~d}$ and rapidly decreased in the $2 \mathrm{wk}$ after the intratracheal administration of IL-1 $\beta$-bound beads (22). The mechanism for the decrease in the IL- $1 \beta$ activity remains to be examined. It also remains to be examined whether or not na-

A
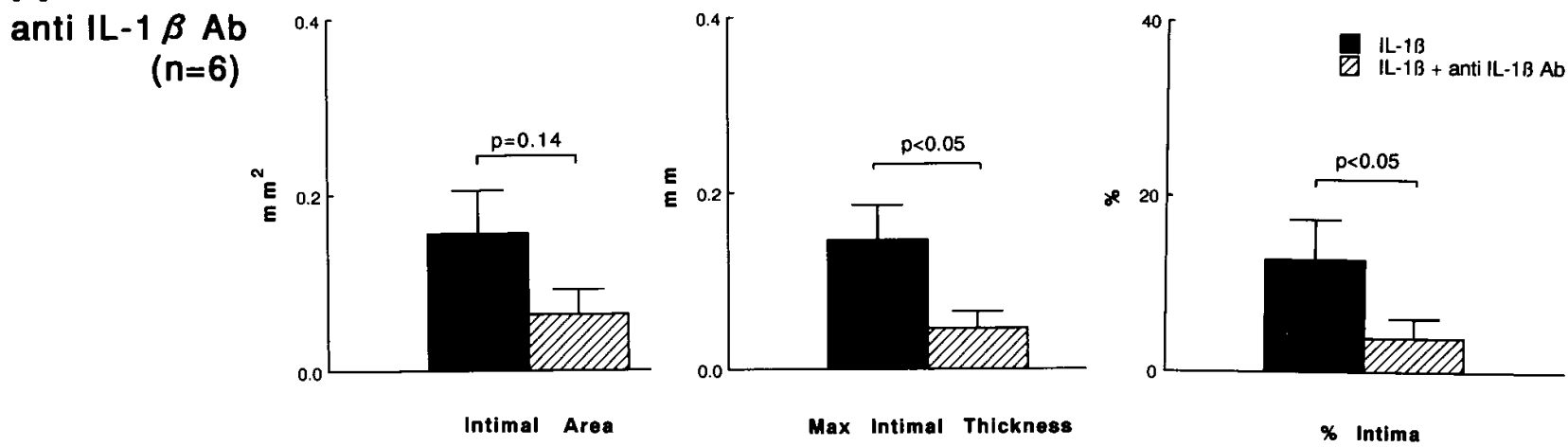

B anti PDGF Ab
$(\mathrm{n}=5)$

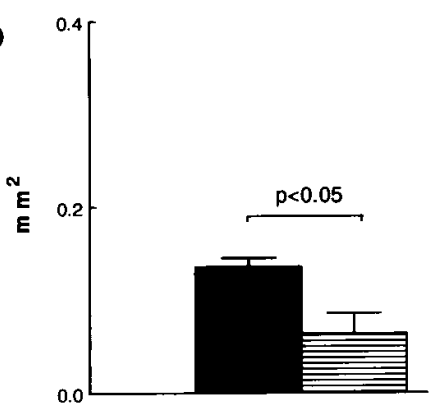

Intimal Area

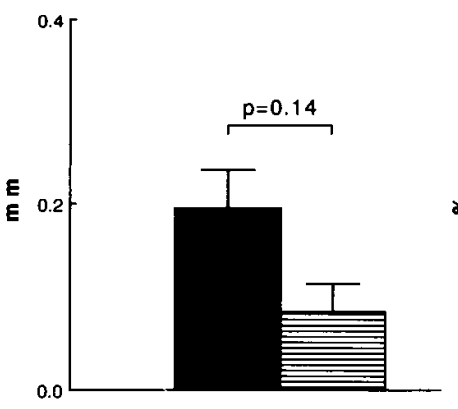

Max Intimal Thickness

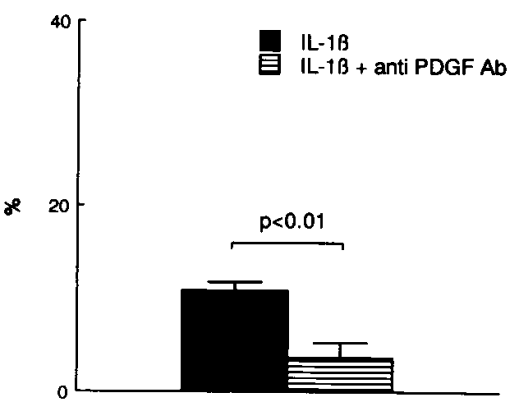

\% Intima

Figure 7. A quantitative analysis of the intimal thickening of the coronary artery segments treated with IL-1 $(2.5 \mu \mathrm{g})$ and IL-1 $(2.5 \mu \mathrm{g})$ plus neutralizing antibody to IL-1 $(5.0 \mathrm{mg})(A)$, and with IL-1 $\beta(2.5 \mu \mathrm{g})$ plus neutralizing antibody to PDGF-AB $(2.5 \mathrm{mg})(B)$. $I L-1 \beta$, a coronary segment treated with IL-1 $\beta$ beads $(2.5 \mu \mathrm{g}) ; I L-1 \beta+$ anti $I L-1 \beta A b$, a coronary segment treated with IL-1 $\beta(2.5 \mu \mathrm{g})$ and a neutralizing antibody to IL-1 $\beta$ (5.0 mg); IL-1 $\beta+$ anti PDGF Ab, a coronary segment treated with IL-1 $\beta(2.5 \mu \mathrm{g})$ and a neutralizing antibody to PDGF (2.5 mg). 
tive porcine inflammatory cytokines, including porcine IL-1 $\beta$, are locally synthesized and released in response to human IL$1 \beta$ by inflammatory cells, smooth muscle cells, endothelial cells, and fibroblasts at the treated coronary segment (13).

Coronary proliferative effects of $I L-1 \beta$. Studies in vitro have shown that IL-1 $\beta$ is not only an inflammatory cytokine but also a growth factor for smooth muscle cells $(7,8)$. However, IL-1 $\beta$ does not have a direct mitogenic activity for smooth muscle cells in vitro, and its proliferative effects are mediated by other growth factors, mainly PDGF, which are induced in and released by fibroblasts and smooth muscle cells in response to IL-1 $\beta$ (23). The present study has confirmed that this also is the case in vivo. It remains to be clarified whether or not other inflammatory cytokines, such as IL- $1 \alpha$ and TNF- $\alpha$, also possess inflammatory/proliferative effects on the coronary artery in vivo.

Mild intimal thickening was also noted at the site treated with control beads. Although special care was taken during the operation to dissect the coronary artery gently and to randomize the coronary segments for the treatment with IL- $1 \beta$ or control beads, these results suggest that in our porcine model the surgical procedure and microbeads also caused a mild adventitial inflammation and/or vascular damage in addition to the effects of IL-1 $\beta$.

Inflammation and coronary artery disease. According to the response-to-injury hypothesis, injurious stimuli are generally thought to affect the vessel wall from the intimal but not from the adventitial surface (1). In this sense, the present results with adventitial inflammation should be interpreted with caution. However, previous pathological studies have demonstrated an infiltration of inflammatory cells and mast cells in the adventitial surface of the coronary artery excised from patients with unstable angina (9) and variant angina (10), respectively. It has been suggested from autopsy findings that adventitial mast cells may potentiate coronary atherosclerosis, vasospasm, and thrombosis in long-term cocaine abusers (11). Recently, it has also been shown that patients with unstable angina have an increased expression of neutrophil and monocyte adhesion receptors, thus indicating an association of an inflammatory reaction with unstable angina (12). It is therefore possible that adventitial inflammatory changes may be involved in the pathogenesis of coronary artery disease.

It is interesting to note that the adventitial treatment with IL-1 $\beta$ resulted in intimal thickening. The results with the neutralizing antibody to PDGF suggest that PDGF substantially mediated the proliferative responses initiated by the adventitial inflammation in our study. Prescott et al. found that adventitial inflammation induced by endotoxin caused leukocyte migration from both the luminal and adventitial side at an early stage ( $2 \mathrm{~d}$ after surgery), followed by intimal thickening at a later stage (1-6 wk after surgery) (21). Their findings suggest that, even in cases of adventitial inflammation, proliferative stimuli affect the vessel wall not only from the adventitial side but also from the luminal side. This finding may also be important for understanding the cellular mechanisms of the vascular proliferation in our model.

Coronary vasospastic responses and $I L-1 \beta$. Another important finding of this study was that coronary vasospastic responses to autacoids were induced at the arteriosclerotic lesions induced by the chronic treatment with IL-1 $\beta$. We have previously developed a swine model of coronary artery spasm $(4-6,16)$. In this original model, coronary spasm was repeat- edly provoked by the autacoids at the atherosclerotic portions that were induced by a combination of endothelial denudation and high-cholesterol feeding $(4-6,16)$. Although a close relationship between coronary spasm and atherosclerotic changes was demonstrated in our original model, exactly what aspect of coronary atherosclerosis is responsible for the occurrence of the spasm remains to be clarified.

The present model demonstrated several new aspects of the pathogenesis of coronary spasm. First, the present study demonstrated that coronary inflammatory changes may be more important in the pathogenesis of coronary spasm than coronary atherosclerotic changes in general. This finding may explain in part why variant angina may be a temporary disorder with a frequent outcome of spontaneous remission (24-26). Second, coronary vasospastic responses were noted in response to the autacoids (serotonin and histamine) but not to prostaglandin $\mathrm{F} 2 \alpha$. This finding may not only exclude the major contribution of the geometric theory (27) but may also suggest the possible alterations in the signal transduction system for vascular smooth muscle contraction. We have recently demonstrated that the intracellular pathway mediated by protein kinase $\mathrm{C}$ plays an important role in the pathogenesis of coronary spasm in our original model (16) and also in the present model (28). The detailed mechanisms for the selective hyperconstriction to the autacoids, however, still remain to be elucidated.

\section{Acknowledgments}

The authors thank Y. Ohmoto and M. Ikeda (The Cellular Technology Institute, Ohtsuka Pharmaceutical Co.) for cooperation in this study, Dr. K. Sueishi (Kyushu University School of Medicine) and Dr. S. Takebayashi (Fukuoka University School of Medicine) for valuable comments on this study, and T. Takebe and M. Mizokami for their technical assistance.

This work was supported in part by grants from Japan's Ministry of Education, Science, and Culture (02404045, 04670540, 05454274, and 07457173 ) and by grants-in-aid from the Sandoz Foundation for Gerontological Research, the Japan Research Foundation for Clinical Pharmacology, and the Japanese Medical Association.

\section{References}

1. Ross, R. 1993. The pathogenesis of atherosclerosis: a perspective for the 1990s. Nature (Lond.). 362:801-809.

2. Munro, J.M., and R.S. Cotran. 1988. Biology of disease. The pathogenesis of atherosclerosis: atherogenesis and inflammation. Lab. Invest. 58:249-261.

3. Hannson, G.K., L. Jonasson, P.S. Seifert, and S. Stemme. 1989. Immune mechanisms in atherosclerosis. Arteriosclerosis. 9:567-578.

4. Shimokawa, H., H. Tomoike, S. Nabeyama, H. Yamamoto, H. Araki, M Nakamura, Y. Ishii, and K. Tanaka. 1983. Coronary artery spasm induced in atherosclerotic miniature swine. Science (Wash. DC). 221:560-562.

5. Shimokawa, H., H. Tomoike, S. Nabeyama, H. Yamamoto, Y. Ishii, K. Tanaka, and M. Nakamura. 1985. Coronary artery spasm induced in miniature swine: angiographic evidence and relation to coronary atherosclerosis. Am. Heart J. 110:300-310.

6. Egashira, K., H. Tomoike, Y. Yamamoto, A. Yamada, Y. Hayashi, and M. Nakamura. 1986. Histamine-induced coronary spasm in regions of intimal thickening in miniature pigs: roles of serum cholesterol and spontaneous or induced intimal thickening. Circulation. 74:826-837.

7. Libby, P., S.J.C. Warner, and G. Friedman. 1988. Interleukin 1: a mitogen for human vascular smooth muscle cells that induces the release of growthinhibitory prostanoids. J. Clin. Invest. 81:487-498.

8. Ikeda, U., M. Ikeda, T. Oohara, S. Kano, and T. Yaginuma. 1990. Mitogenic action of interleukin- $1 \alpha$ on vascular smooth muscle cells mediated by PDGF. Atherosclerosis. 84:183-188.

9. Kohchi, K., S. Takebayashi, T. Hiroki, and M. Nobuyoshi. 1985. Significance of adventitial inflammation of the coronary artery in patients with unstable angina: results at autopsy. Circulation. 71:709-716. 
10. Forman, M.B., J.A. Oates, D. Robertson, R.M. Robertson, L.J. Roberts II, and R. Virmani. 1985. Increased adventitial mast cells in a patient with coronary spasm. N. Engl. J. Med. 313:1138-1141.

11. Kolodgie, F.D., R. Virmani, J.F. Cornhill, E.E. Herderick, and J. Smialek. 1991. Increase in atherosclerosis and adventitial mast cells in cocaine abusers: an alternative mechanism of cocaine-associated coronary vasospasm and thrombosis. J. Am. Coll. Cardiol. 17:1553-1560.

12. Mazzone, A., S. De Servi, G. Ricevuti, I. Mazzucchelli, G. Fossati, D. Pasotti, E. Bramucci, L. Angoli, F. Marsico, G. Specchia, and A. Notario. 1993. Increased expression of neutrophil and monocyte adhesion molecules in unstable coronary artery disease. Circulation. 88:358-363.

13. Dinarello, C.A. 1988. Biology of interleukin 1. FASEB J. 2:108-115.

14. Moyer, C.F., D. Sajuthi, H. Tulli, and J.K. Williams. 1991. Synthesis of IL-1 alpha and IL-1 beta by arterial cells in atherosclerosis. Am. J. Pathol. 138: 951-960.

15. Kita, M., Y. Ohmoto, Y. Hirai, N. Yamaguchi, and J. Imanishi. 1992. Induction of cytokines in human peripheral blood mononuclear cells by mycoplasmas. Microbiol. Immunol. 36:507-516.

16. Ito, A., H. Shimokawa, R. Nakaike, T. Fukai, M. Sakata, T. Takayanagi, K. Egashira, and A. Takeshita. 1994. Role of protein kinase C-mediated pathway in the pathogenesis of coronary artery spasm in a swine model. Circulation. 90:2425-2431.

17. Wallenstein, S., C.L. Zucher, and J.L. Fleiss. 1980. Some statistical methods useful in circulation research. Circ. Res. 47:1-9.

18. Nabel, E.G., G. Plautz, F. Boyce, J.C. Stanley, and G.J. Nabel. 1989. Recombinant gene expression in vivo within endothelial cells of the arterial wall. Science (Wash. DC). 244:1342-1344.

19. Nabel, E.G., G. Plautz, and G.J. Nabel. 1990. Site-specific gene expression in vivo by direct gene transfer into the arterial wall. Science (Wash. DC).
249:1285-1288.

20. Nimmo, W.S., J.G. Todd. 1985. Fentanyl by constant rate i.v. infusion for postoperative analgesia. Br. J. Anaesth. 57:250-254.

21. Prescott, M.F., C.K. McBride, and M. Court. 1989. Development of intimal lesions after leukocyte migration into the vascular wall. Am. J. Pathol. 135 835-846.

22. Kasahara, K., K. Kobayashi, Y. Shikama, I. Yoneya, K. Soejima, H. Ide, and T. Takahashi. 1988. Direct evidence for granuloma-inducing activity of interleukin-1. Induction of experimental pulmonary granuloma formation in mice by interleukin-1-coupled beads. Am. J. Pathol. 130:629-638.

23. Raines, E.W., S.K. Dower, and R. Ross. 1989. Interleukin-1 mitogenic activity for fibroblasts and smooth muscle cells is due to PDGF-AA. Science (Wash. DC). 243:393-396.

24. Shimokawa, H., K. Nagasawa, T. Irie, S. Egashira, K. Egashira, T. Sagara, Y. Kikuchi, and M. Nakamura. 1988. Clinical characteristics and longterm prognosis of patients with variant angina. A comparative study between Western and Japanese populations. Int. J. Cardiol. 18:331-349.

25. Waters, D.D., A. Bouchard, and P. Theroux. 1983. Spontaneous remission as frequent outcome of variant angina. J. Am. Coll. Cardiol. 2:195-199.

26. Tashiro, H., H. Shimokawa, S. Koyanagi, and A. Takeshita. 1993. Clinical characteristics of patients with spontaneous remission of variant angina. Jpn. Circ. J. 57:117-122.

27. MacAlpin, R.N. 1980. Contribution of dynamic vascular wall thickening of luminal narrowing during coronary arterial constriction. Circulation. 61:296301.

28. Kadokami, T., H. Shimokawa, A. Ito, Y. Fukumoto, T. Takayanagi, and K. Egashira. 1994. Activation of protein kinase C induces coronary vasospasm at the interleukin-1 $\beta$-induced inflammatory/proliferative lesion in a swine model. Circulation. 90:I-258 